\title{
Electrooxidation of Nitrite Ions on Gold/Polyaniline/Carbon Paste Electrode
}

\author{
Mohammad Etesami ${ }^{1,2, *}$, Nurul S. N. M. S. Chandran ${ }^{2}$, M. Hazwan Hussin ${ }^{2}$, Adnan Ripin ${ }^{1,3}$, \\ Rohana Adnan ${ }^{2}$, Amat Ngilmi A. Sujari ${ }^{2}$, Norita Mohamed ${ }^{2, *}$ \\ ${ }^{1}$ Advanced Materials Research Group, Institute of Hydrogen Energy, Universiti Teknologi Malaysia, \\ 54100 Kuala Lumpur, Malaysia \\ ${ }^{2}$ School of Chemical Sciences, Universiti Sains Malaysia, 11800 Minden, Penang, Malaysia \\ ${ }^{3}$ Faculty of Chemical Engineering, Universiti Teknologi Malaysia, 81310 UTM Johor Bahru, Johor, \\ Malaysia \\ *E-mail: md.etesami@gmail.com,mnorita@usm.my
}

doi: $10.20964 / 2016.10 .32$

Received: 12 April 2016 / Accepted: 11 June 2016 / Published: 6 September 2016

\begin{abstract}
Nitrite ions can penetrate from fertilizers into underground water and consequently contaminate the water and food sources. A facile two-step electrochemical method was used to fabricate gold/polyaniline/carbon paste electrode (Au/PAni/CPE) for nitrite sensing. The Au/PAni/CPE was visualized and characterized by scanning electron microscopy, energy-dispersed X-ray spectroscopy, $\mathrm{X}$-ray diffraction and electrochemical methods. The electrocatalytic activity of bare CPE, PAni/CPE and $\mathrm{Au} / \mathrm{PAni} / \mathrm{CPE}$ toward the electrooxidation of nitrite was examined and compared via cyclic voltammetry. To obtain the optimal condition for fabrication of the electrode, the number of cycles in cyclic voltammetry for synthesis of polyaniline and the deposition time in potentiostatic deposition of gold were optimized with respect to the electrooxidation of nitrite. In a phosphate buffer solution (PBS, $\mathrm{pH} 7.0$ ), the peak current was linear to the concentration of nitrite in the range from $3.8 \times 10^{-5} \mathrm{M}$ to $1.0 \times 10^{-3} \mathrm{M}$ with a detection limit of $2.5 \times 10^{-5} \mathrm{M}$. The interference effect on the nitrite detection was also studied. The proposed method was also employed for the determination of nitrite in rain and lake water samples.
\end{abstract}

Keywords: Nitrite, Carbon paste electrode, Polyaniline, Gold particles, Electrocatalysis

\section{$\underline{\text { FULL TEXT }}$}

(C) 2016 The Authors. Published by ESG (www.electrochemsci.org). This article is an open access article distributed under the terms and conditions of the Creative Commons Attribution license (http://creativecommons.org/licenses/by/4.0/). 